\title{
Single Center Experience with Deceased Donor Kidney Transplantation in Patients Aged 70 and Older: A Matched-Pair Cohort Study
}

Umar Farooq ${ }^{1}$, Yousef Al-Shraideh ${ }^{1}$, Ravi Katari, BS ${ }^{1}$, Alan C. Farney ${ }^{1}$, Jeffrey Rogers ${ }^{1}$, Amudha Palanisamy $^{2}$, Giuseppe Orlando $^{1}$, Amber Reeves-Daniel ${ }^{2}$, William Doares $^{3}$, Scott Kaczmorski ${ }^{3}$, Michael D. Gautreaux ${ }^{1}$, Samy S. Iskandar ${ }^{4}$, Gloria Hairston ${ }^{1}$, Margaret Mangus ${ }^{1}$, Elizabeth Brim ${ }^{1}$ and Robert J. Stratta $^{1 *}$

${ }^{1}$ Departments of General Surgery, Wake Forest School of Medicine, USA

${ }^{2}$ Departments of Internal Medicine, Wake Forest School of Medicine, USA

${ }^{3}$ Departments of Pharmacy, Wake Forest School of Medicine, USA

${ }^{4}$ Departments of Pathology, Wake Forest School of Medicine, USA

*Corresponding author: Robert J Stratta, Director of Transplantation, Wake Forest School of Medicine, General Surgery, Medical Center Blvd, Winston-Salem, NC 27157, USA, Tel: 001-336-716-0548; Fax: 001-336-713-5055; E-mail: rstratta@wakehealth.edu

Rec date Jul 01, 2014, Acc date: Sep 08, 2014, Pub date: Sep 10, 2014

Copyright: ( 2014 Farooq U, et al. This is an open-access article distributed under the terms of the Creative Commons Attribution License, which permits unrestricted use, distribution, and reproduction in any medium, provided the original author and source are credited

\begin{abstract}
The purpose of this study was to compare mate deceased donor (DD) kidney transplant (KT) outcomes in patients $\geq 70$ versus $<70$ years of age in a matched-pair analysis.

Methods: Single center retrospective review of adult KT cases.

Results: From 5/03 to 3/12, we identified 33 DD kidney pairs that met the above criteria. Mean donor age and BMI were 52 years and $27.4 \mathrm{~kg} / \mathrm{m}^{2}$, respectively, including $19(58 \%)$ expanded criteria donors. Mean recipient ages were 73.6 and 55.3 years in the 2 groups $(p<0.01)$. No significant differences were noted in multiple recipient and transplant characteristics in the older and younger groups. With a mean follow-up of 58 months, actual patient (79\% older versus $94 \%$ younger, $p=0.15$ ) and kidney graft survival ([KGS] $64 \%$ older versus $67 \%$ younger) rates were comparable. Two-year patient ( $97 \%$ older versus $94 \%$ younger) and KGS ( $91 \%$ older versus $82 \%$ younger) rates revealed few early deaths or graft losses in the older group. Death-censored KGS (81\% older versus $69 \%$ younger) rates demonstrated that the older group had more deaths with functioning grafts (DWFG, $21 \%$ versus $3 \%, p=0.05$ ). Mean length of initial hospital stay, renal function, and rates of delayed graft function, acute rejection, major infection, re-operations and readmissions were comparable. In 13 patients aged 75 years and older, the incidence of DWFG was $31 \%$ in patients compared to $15 \%$ in patients aged $70-74$ ( $p=0.33$ compared to those $>75$ ), and $3 \%$ in all 33 younger patients $(p=0.02$ compared to those $>75)$. The timing of DWFG was at a mean of 40.5 months in patients aged 75 and older compared to 72 months for those aged $70-74$ years.
\end{abstract}

Conclusions: When controlling for donor factors in a paired kidney analysis, medium-term outcomes are largely influenced by a higher incidence of DWFGs in the elderly, particularly in patients aged 75 and older.

Keywords: Death with functioning graft; Deceased donor kidney transplantation; Elderly; End-stage renal disease; Expanded criteria donors; Outcomes; Paired kidneys; Recipient age

\section{Introduction}

An ever-increasing proportion of elderly patients are receiving renal replacement therapies for end stage renal disease (ESRD) in the second decade of the new millennium [1]. Age is an important determinant in kidney transplantation (KT) [1-6]. Increasing recipient age remains a major risk factor for mortality following KT, with the risk of death increasing proportionately with advanced age and specific comorbidities at the time of KT [5-13]. Although the propriety of using deceased donor (DD) organs for KT in the elderly has been questioned [14-17], recent literature suggests that donor and recipient agematched KT in both elderly and younger recipients is medically and ethically warranted compared to dialysis for the treatment of ESRD [18-22]. Although conventional wisdom once held that neither older donors nor older recipients ought to participate in $\mathrm{KT}$, this paradigm has changed given the success of age-matching and the general superiority of $\mathrm{KT}$ as a modality of renal replacement therapy regardless of recipient age [1-25].

Nevertheless, population-based studies suggest that there is still a reluctance to place older patients on the kidney waiting list $[2,14-18,26]$. A recent study demonstrated that $46 \%$ of KT candidates $\geq 60$ years of age placed on the waiting list will actually die before receiving a DD KT [27]. Older age is also used as a surrogate for disease burden, functional status, co-morbidities and hospitalization $[28,29]$. The reluctance to accept older candidates for the kidney waiting list is mostly due to co-morbidities (e.g., cardiovascular disease, infection, and malignancy), shorter life expectancy, and the increased risk of death with a functioning graft (DWFG) [2-13,30]. With tailored immunosuppressive regimens, advances in surgical techniques, and better peri-operative management, the reluctance to incorporate elderly patients into the recipient pool has in part been mitigated. Outcomes of DD KT in patients $\geq 70$ years of age are understudied [31-35]. The purpose of this study was to analyze outcomes in patients $\geq 70$ compared to those $<70$ years of age in a matched-paired donor kidney analysis that largely controls for donor 
Citation: Farooq U, Al-Shraideh Y, Katari R, Farney AC, Rogers J, et al. (2014) Single Center Experience with Deceased Donor Kidney Transplantation in Patients Aged 70 and Older: A Matched-Pair Cohort Study. J Transplant Technol Res 4: 135. doi: 10.4172/2161-0991.1000135

Page 2 of 7

and preservation factors so that recipient factors that influence outcomes could be isolated to stratify risk and determine the optimal utilization of DD kidneys.

\section{Patients and Methods}

\section{Design and setting}

We conducted a retrospective chart review of all DD KTs performed at our center from 10/1/01 to 3/1/12 (minimum 22 months follow-up). During this 10.5 year study period, we identified 33 pairs of DD kidneys transplanted at our center in which one kidney was transplanted into a patient $\geq$ age 70 and the mate kidney from the same donor was transplanted into a patient $<70$ years of age.

\section{Definitions}

In addition to recipient factors, outcomes were evaluated according to DD category. Expanded criteria donors (ECD) were defined by United Network for Organ Sharing (UNOS) criteria [36]. For purposes of this study, any DD not meeting ECD criteria was defined as a standard criteria donor (SCD). Delayed graft function (DGF) was defined as the need for dialysis for any reason in the first week posttransplant. Renal allograft loss was defined as DWFG, transplant nephrectomy, return to dialysis, retransplantation, or return to the pretransplant SCr level.

\section{Recipient evaluation and selection}

At our center, no specific upper age limit was an absolute contraindication to $\mathrm{KT}$, although the oldest recipient in this series was 84 years at the time of KT. All patients underwent a comprehensive pre-transplant medical, psychosocial, and financial evaluation, with emphasis placed on the cardiovascular system to determine operative risks and physiologic age [37]. Specific exclusion criteria in the elderly included the presence of dementia, nursing home residence, poor overall functional status or frailty, lack of social support, advanced disease or organ failure in an extra-renal organ system, recent malignancy, or severe cardiac or vascular disease. Patients were initially selected for transplantation according to UNOS guidelines $[37,38]$. Whenever possible, however, marginal donor kidneys were used by matching estimated renal functional mass to recipient nephron need [38]. In this setting, recipient selection was usually not by standard kidney allocation but was based on age matching and identifying low immunological risk patients such as primary transplant, recipient age $>40$ years, human leukocyte antigen (HLA) matching, low panel reactive antibody (PRA) level (usually $0 \%$ ), body mass index (BMI) $<30 \mathrm{~kg} / \mathrm{m}^{2}$, and informed consent [37,38].

\section{Immunosuppression}

DD kidney transplant patients received depleting antibody induction with either rabbit antithymocyte globulin (rATG) at a dose of $1.5 \mathrm{mg} / \mathrm{kg}$ (maximum dose, $150 \mathrm{mg}$ based on actual body weight) for 3-7 doses depending on initial graft function or alemtuzumab 30 $\mathrm{mg}$ intravenous as a single intra-operative dose [37,38]. Maintenance immunosuppression consisted of tacrolimus (TAC), mycophenolate mofetil (MMF), and rapid tapering doses of steroids or early steroid withdrawal based on immunological risk stratification [39]. Specific data regarding drug dosing, target levels, and anti-infective prophylaxis have been previously published [37-39].

\section{Statistical Analysis}

Data were compiled from both prospective and retrospective data bases, with confirmation by medical record review in accordance with Institutional Review Board guidelines and approval. Categorical data were summarized as proportions and percentages and continuous data were summarized as means and standard deviations. Univariate analysis was performed by the Student's $t$ test for continuous variables, the chi-square test for categorical variables, and Fisher's exact test when data were sparse. Actual, actuarial, and death-censored survival rates were determined. A two-tailed $\mathrm{p}$-value of $<0.05$ was considered to be significant.

\section{Results}

From $5 / 03$ to $3 / 12$, we identified 33 DD kidney pairs that met the inclusion criteria. Mean donor age and BMI were $51.7 \pm 16.9$ years and $27.4 \pm 6.8 \mathrm{~kg} / \mathrm{m}^{2}$, respectively, including 19 (58\%) expanded criteria donors. Mean recipient ages were $73.6 \pm 2.7$ and $55.3 \pm 11.4$ years in the 2 groups $(\mathrm{p}<0.01)$.

\section{Donor characteristics}

The majority $(\mathrm{N}=25,76 \%)$ of DDs were donation after brain death (16 ECD, 9 SCD) whereas the remaining $8(24 \%)$ were donation after cardiac death (DCD) DDs (5 SCD, 3 ECD). Most of the DDs were from our local donor service area $(64 \%, \mathrm{n}=21)$ whereas the remaining 12 kidney pairs (36\%) were imported from other organ procurement organizations. Many were refused by multiple centers and were targeted for discard. Mean KDRI and KDPI were $1.27 \pm 0.48$ and $68 \pm$ $39.6 \%$, respectively. Twenty donors were male and 30 were Caucasian. Most of the DDs (64\%) had a history of hypertension and 39\% had a history of diabetes mellitus. Mean estimated glomerular filtration rate (eGFR) was $94.7 \pm 37.0 \mathrm{ml} / \mathrm{min}$ and mean terminal SCr level was $1.1 \pm$ $0.9 \mathrm{mg} / \mathrm{dl}$. Major causes of death included stroke $(60 \%)$ and trauma (21\%). Fourteen $(42 \%)$ of the donors were $\geq$ age 60 . Mean CIT was $24.7 \pm 7.9$ hours. Following procurement, 54 (82\%) of the kidneys were managed with machine preservation for variable periods of time (mean pump time $14.8 \pm 5.8$ hours). Mean terminal pump flow rate was $121 \pm 31 \mathrm{ml} / \mathrm{min}$ and mean terminal resistance value was $0.20 \pm$ $0.10 \mathrm{~mm} \mathrm{Hg} / \mathrm{ml} / \mathrm{min}$.

\section{Recipient characteristics}

Table 1 shows recipient demographic and transplant characteristics between the 2 groups. No significant differences were noted in recipient gender, race, mean BMI, mean time on dialysis or waiting time, type of dialysis, preemptive transplants, retransplants, diabetes as the cause of renal failure, or induction and maintenance immunosuppression in the older and younger recipient groups. However, the proportion of patients with 4-6 HLA mismatches (73\% older versus $94 \%$ younger, $\mathrm{p}=0.04$ ) was higher in the younger group whereas patients with a PRA level $>10 \%$ (33\% older versus $6 \%$ younger, $\mathrm{p}=0.01$ ) was greater in the older group. Mean cold ischemia was similar $(24.6 \pm 8.8$ versus $25.1 \pm 7.1$ hours $)$ in the older and younger recipient groups as was the mean (57.8 versus 58 months) duration of follow-up. 
Citation: Farooq U, Al-Shraideh Y, Katari R, Farney AC, Rogers J, et al. (2014) Single Center Experience with Deceased Donor Kidney Transplantation in Patients Aged 70 and Older: A Matched-Pair Cohort Study. J Transplant Technol Res 4: 135. doi: 10.4172/2161-0991.1000135

Page 3 of 7

\begin{tabular}{|c|c|c|c|}
\hline $\begin{array}{l}\text { Variable } \\
\text { Mean } \pm \text { SD }\end{array}$ & Older recipients $(n=33)$ & Younger recipients $(n=33)$ & P-value \\
\hline Age (years) & $73.6 \pm 2.7$ & $55.3 \pm 11.4$ & $<0.001$ \\
\hline Males & $16(48 \%)$ & $11(33 \%)$ & NS \\
\hline African American & $8(24 \%)$ & $13(39 \%)$ & NS \\
\hline Recipient BMI (kg/m²) & $26.5 \pm 4.7$ & $26.6 \pm 5.3$ & NS \\
\hline Duration of dialysis (months) & $29.2 \pm 22.5$ & $29.0 \pm 26.6$ & NS \\
\hline Time on waiting list (months) & $15 \pm 11$ & $16 \pm 16.5$ & NS \\
\hline \multicolumn{4}{|l|}{ Renal replacement therapy pretransplant } \\
\hline -Hemodialysis & $24(73 \%)$ & $24(73 \%)$ & NS \\
\hline -Peritoneal dialysis & $4(12 \%)$ & $6(18 \%)$ & NS \\
\hline Preemptive transplant & $5(15 \%)$ & $3(9 \%)$ & NS \\
\hline Retransplant & $1(3 \%)$ & $1(3 \%)$ & NS \\
\hline \multicolumn{4}{|l|}{ Number of HLA mismatches } \\
\hline-0 & 0 & 0 & 0.04 \\
\hline$-1-3$ & 9 & 2 & \\
\hline$-4-6$ & 24 & 31 & \\
\hline \multicolumn{4}{|l|}{ Cause of end stage renal disease } \\
\hline Diabetes & $14(42 \%)$ & $10(30 \%)$ & NS \\
\hline Hypertension & $9(27 \%)$ & $3(9 \%)$ & \\
\hline Other & $10(30 \%)$ & $20(61 \%)$ & \\
\hline \multicolumn{4}{|l|}{ Panel reactive antibody levels } \\
\hline$-0-10 \%$ & 22 & 31 & 0.01 \\
\hline$-11-49 \%$ & 5 & 1 & \\
\hline$-50-100 \%$ & 6 & 1 & \\
\hline Cold ischemia (hours) & $24.6 \pm 8.8$ & $25.1 \pm 7.1$ & NS \\
\hline \multicolumn{4}{|l|}{ Induction immunosuppression } \\
\hline -Alemtuzumab & 25 & 25 & NS \\
\hline -Rabbit antithymocyte globulin & 8 & 7 & \\
\hline -Basiliximab & 0 & 1 & \\
\hline \multicolumn{4}{|l|}{ Maintenance Immunosuppression } \\
\hline - Tacrolimus + Mycophenolate Mofetil & 12 & 12 & NS \\
\hline - Tacrolimus + Mycophenolate Mofetil + Prednisone & 17 & 18 & \\
\hline - Cyclosporine + Mycophenolate Mofetil & 0 & 2 & \\
\hline - Cyclosporine + Mycophenolate Mofetil + Prednisone & 4 & 1 & \\
\hline
\end{tabular}

Table 1: Demographic and transplant characteristics between older and younger recipient groups.

\section{Transplant outcomes}

Table 2 shows outcomes between the 2 groups. Actual patient (79\% older versus $94 \%$ younger, $\mathrm{p}=0.15$ ) and kidney graft survival ([KGS] $64 \%$ older versus $67 \%$ younger) rates were comparable. Two-year patient ( $97 \%$ older versus $94 \%$ younger) and KGS (91\% older versus $82 \%$ younger) rates revealed few early deaths or graft losses in the older recipient group. Two early deaths (within 1 month) occurred in the younger group whereas the 7 deaths in the older group occurred at a mean of 59 months post-transplant. The 2 early deaths in the younger group were secondary to sepsis and pulmonary embolism; both in patients with primary nonfunction. Causes of death in the older group included cardiovascular (4), cerebrovascular (1), 
Citation: Farooq U, Al-Shraideh Y, Katari R, Farney AC, Rogers J, et al. (2014) Single Center Experience with Deceased Donor Kidney Transplantation in Patients Aged 70 and Older: A Matched-Pair Cohort Study. J Transplant Technol Res 4: 135. doi: 10.4172/2161-0991.1000135

Page 4 of 7

respiratory failure (1), and malignancy (1). Actuarial patient ( $\mathrm{p}=0.09)$, uncensored kidney graft and death-censored KGS $(\mathrm{p}=\mathrm{NS})$ rates in the older and younger groups are shown in (Figures 1-3), respectively. Death-censored KGS ( $81 \%$ older versus $69 \%$ younger, $\mathrm{p}=0.37$ ) rates demonstrated that the older group had more deaths with functioning grafts (DWFG, 21\% versus 3\%, $\mathrm{p}=0.05$ ) but otherwise exhibited a slightly higher KGS rate in the absence of mortality. Mean length of initial hospital stay and rates of DGF, acute rejection, major infection, re-operations and readmissions were comparable. Renal function at 1 and 12 months was similar in the 2 groups (Table 2).

\begin{tabular}{|c|c|c|c|}
\hline $\begin{array}{l}\text { Variable } \\
\text { Mean } \pm \text { SD }\end{array}$ & Older recipients $(n=33)$ & Younger recipients $(n=33)$ & P-value \\
\hline Patient survival & $26(79 \%)$ & $31(94 \%)$ & 0.15 \\
\hline Kidney graft survival & $21(64 \%)$ & $22(67 \%)$ & NS \\
\hline Follow-up (months) & $60 \pm 24$ & $58 \pm 22$ & NS \\
\hline 2-year patient survival & $32(97 \%)$ & $31(94 \%)$ & NS \\
\hline 2-year kidney graft survival & $30(91 \%)$ & 27 (82\%) & NS \\
\hline Death-censored graft survival & $21 / 26(81 \%)$ & $22 / 32(69 \%)$ & 0.37 \\
\hline Death with a functioning graft & $7(21 \%)$ & $1(3 \%)$ & 0.05 \\
\hline Delayed graft function & $11(33 \%)$ & $8(24 \%)$ & NS \\
\hline Length of initial hospital stay (days) & $6.4 \pm 2.0$ & $5.9 \pm 2.4$ & NS \\
\hline Acute rejection & $6(18 \%)$ & $3(9 \%)$ & NS \\
\hline Major infection & $7(21 \%)$ & $5(15 \%)$ & NS \\
\hline Surgical complications & $3(9 \%)$ & 0 & NS \\
\hline Re-admissions & $14(42 \%)$ & $10(30 \%)$ & NS \\
\hline Serum creatinine (mg/dl): 1 month & $1.8 \pm 1.0$ & $1.8 \pm 0.9$ & NS \\
\hline 12 months & $1.5 \pm 0.9$ & $1.7 \pm 0.9$ & NS \\
\hline aMDRD GFR (ml/min): 1 month & $43 \pm 16$ & $46 \pm 21$ & NS \\
\hline 12 months & $50 \pm 17$ & $50 \pm 22$ & NS \\
\hline
\end{tabular}

Table 2: Outcomes.

In 13 patients aged 75 years and older, actual patient survival $(69 \%$ $>75$ versus $100 \%$ younger, $\mathrm{p}=0.096)$, and $\mathrm{KGS}(46 \%>75$ versus $77 \%$ younger, $\mathrm{p}=0.22$ ) rates were numerically lower compared to the younger matched pairs. When comparing patients aged 75 years and above to the remaining 20 older patients aged 70-74 years, patient survival $(69 \%>75$ versus $85 \% 70-74, \mathrm{p}=0.39)$, KGS $(46 \%>75$ versus $75 \% 70-74, \mathrm{p}=0.14)$, and death-censored KGS $(67 \%>75$ versus $88 \%$ $70-74, \mathrm{p}=0.30$ ) rates were again slightly but not statistically lower in the oldest group. The incidences of DWFG were $31 \%$ in patients aged 75 and older, $15 \%$ in patients aged $70-74(\mathrm{p}=0.33$ compared to those $>75$ ), and $3 \%$ in all 33 younger patients ( $\mathrm{p}=0.02$ compared to those >75). The timing of DWFG was at a mean of 40.5 months in patients aged 75 and older compared to 72 months for those aged 70-74 years.

\section{Outcomes According to DD Category}

Not surprisingly, actual KGS rates in the older recipient group were highest with kidneys from SCDs (88.9\%) and lower with kidneys from ECDs (56.3\%) and DCD donors (50\%). Actual KGS rates in the younger recipient group were likewise highest with kidneys from SCDs (88.9\%), intermediate with kidneys from ECDs (68.8\%), and lowest with kidneys from DCD donors (37.5\%). Five of the 8 DWFGs occurred in older patients receiving kidneys from ECDs, similar to the overall distribution of ECD kidneys in the study population. Deathcensored KGS rates in the older recipient group were 100\% with kidneys from SCDs, $81.8 \%$ with kidneys from ECDs, and 57.1\% with kidneys from DCD donors. The corresponding death-censored KGS rates in the younger recipient group were $88.9 \%$ with kidneys from SCDs, $68.8 \%$ with kidneys from ECDs, and $42.9 \%$ with kidneys from DCD donors. From a death-censored perspective, the optimal utilization of an ECD kidney was transplantation into an older recipient. 
Citation: Farooq U, Al-Shraideh Y, Katari R, Farney AC, Rogers J, et al. (2014) Single Center Experience with Deceased Donor Kidney Transplantation in Patients Aged 70 and Older: A Matched-Pair Cohort Study. J Transplant Technol Res 4: 135. doi: 10.4172/2161-0991.1000135

Page 5 of 7

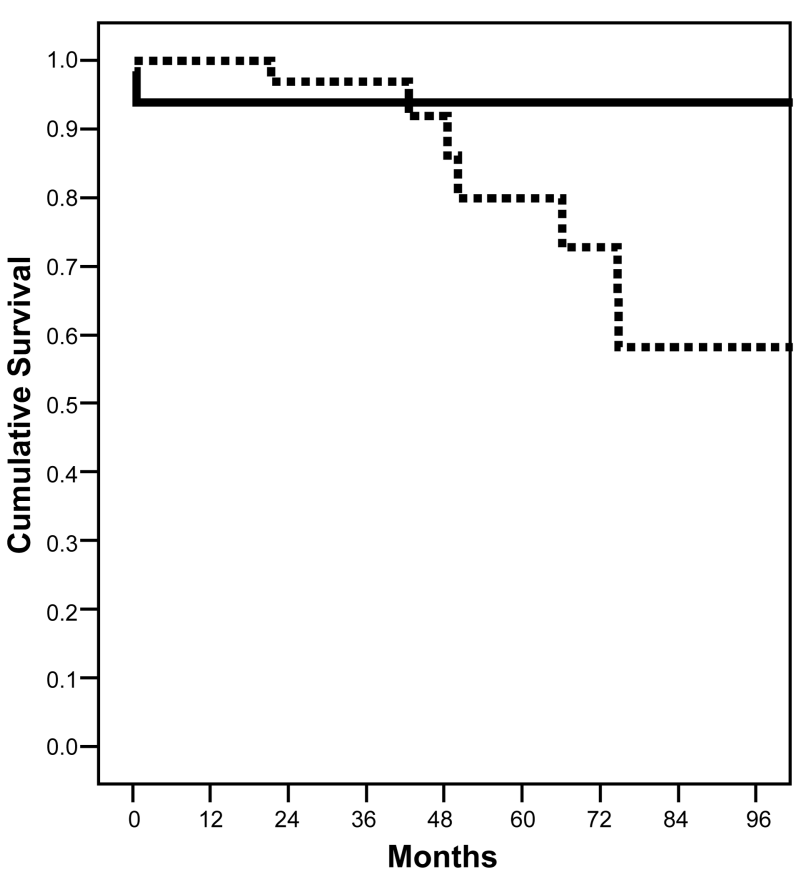

Figure 1: Actuarial (death-censored) kidney graft survival in elderly and younger recipients in paired kidney analysis $(\mathrm{p}=0.09)$.

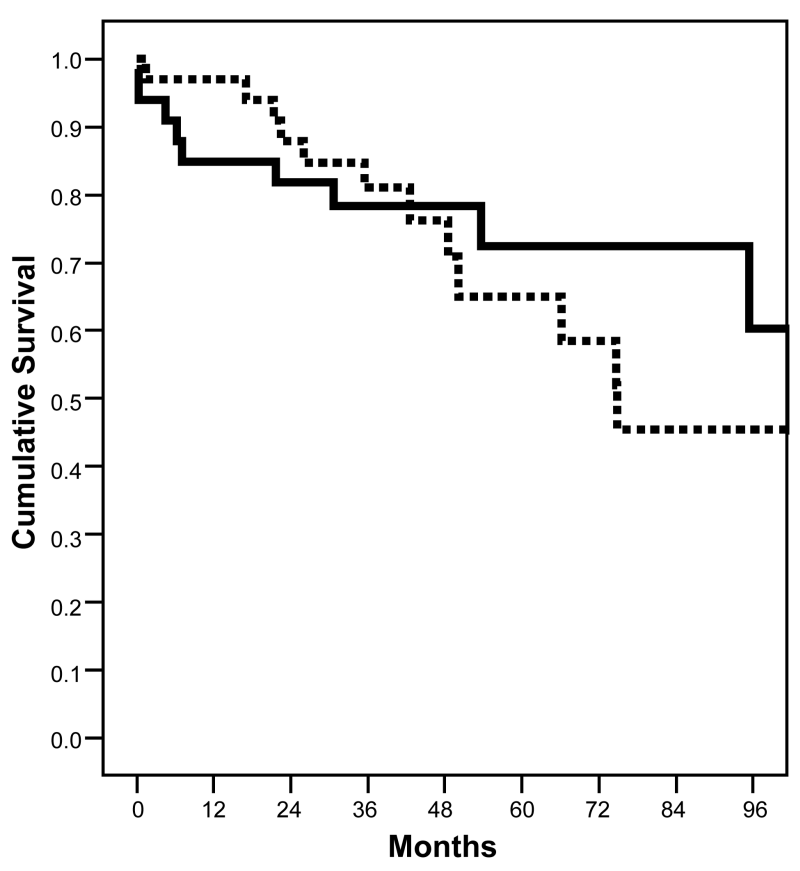

Figure 2: Actuarial (death-censored) kidney graft survival in elderly and younger recipients in paired kidney analysis $(\mathrm{p}=0.09)$.

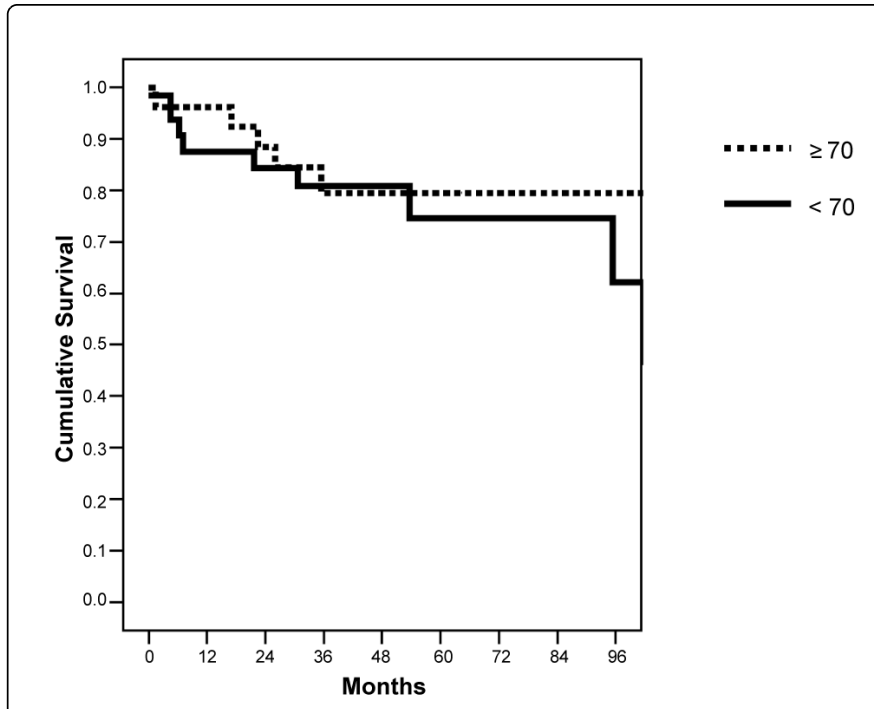

Figure 3: Actuarial (death-censored) kidney graft survival in elderly and younger recipients in paired kidney analysis $(\mathrm{p}=0.09)$.

\section{Discussion}

The number of younger ( $<50$ years) candidates on the kidney waiting list in the US has declined since 1990. During the same time, the number of candidates aged 50 to 69 years has doubled and those aged 70 years or more quintupled [1,40]. This is likely due, in part, to the rapidly increasing senior ( $>65$ years) population in the US, which currently account for nearly half of incident patients with ESRD $[1,40]$. In short, current demographic trends suggest an increasing proportion of elderly patients in an already rising ESRD population. To add to this dilemma, waiting times and mortality on the kidney waiting list are increasing significantly because of the increasing disparity between the growing number of KT candidates and the static organ supply $[1,27,28,40]$. It is imperative that transplant centers are good stewards of a scarce resource and optimize utilization of DD kidneys. Given that $\mathrm{KT}$ is not only the most clinically effective, but also cost-effective modality for ESRD [41], critical analyses of outcomes in elderly recipients are necessary because kidney lifespan is reduced in this setting because of an increasing number of DWFGs [2-18].

One might contend that an important goal of $\mathrm{KT}$ is to have the transplanted organ "outlive" the patient. In other words, DWFG could be considered the ultimate endpoint of transplantation with the caveat that death was neither accelerated nor related to the consequences of transplantation and the requisite chronic immunosuppression. However, another important objective is to avoid large "mismatches" of donor kidney and recipient longevity so as to not lose kidney graft life-years. There is no question that a spectrum of DD kidney quality exists and that many recovered kidneys are discarded because of concerns about both initial graft function as well as expected kidney lifespan [1]. Unfortunately, predictive tools and scoring systems are not always reliable and therein lay the challenge of determining not only the "usability" of a given kidney but also choosing the most appropriate recipient. Because older patients have a limited life expectancy and many kidneys from older donors are discarded, it is not unreasonable to age-match donors and recipients as a surrogate for matching both functional capacity and anticipated lifespan [19-22]. 
It is important to emphasize that the reason why we received both kidneys from each of these donors is because other centers refused the kidney offers. Many of these kidneys may have been discarded in the absence of our utilization and therefore were not appropriate for standard allocation. Consistent with recent literature regarding $\mathrm{KT}$ in elderly recipients, our findings demonstrate that medium-term outcomes are largely influenced by a higher incidence of DWFG in the elderly, particularly for those aged 75 and older [2-36]. Not surprisingly, the incidence and timing post-transplant of DWFG was directly related to older recipient age with patients aged 75 and older having both a higher incidence of and shorter interval post-transplant to the occurrence of DWFG.

However, a unique aspect of our study is the matched-pair cohort analysis, which in effect controls for donor quality, minimizes donor variability and bias, and provides a robust control group in an attempt to isolate transplant and recipient-related factors. Because the mean donor age in our study was 52 years and $42 \%$ were standard criteria donors, one might question whether placing these kidneys in older patients results in unrealized graft years. However, the finding that uncensored medium-term graft survival outcomes are similar irrespective of recipient age group would suggest not a loss of graftyears but rather that the causes of graft loss differ by age when one controls for donor and preservation factors. Previous studies comparing outcomes of mate kidneys transplanted sequentially to different recipients have generally been small or single center reports and have demonstrated concordance of outcomes with respect to the incidence of DGF, renal function, and KGS provided that cold ischemia times are not excessive for the second kidney [42-46].

In one of the few reports analyzing the effect of recipient age in a paired kidney analysis, Debska-Slizien et al. examined 44 pairs of mate kidneys and used an age of 60 years to differentiate between older and younger recipients [47]. At one year follow-up, patient (93.2\% versus 95.5\%), KGS (88.6\% versus $86.3 \%$ ) and death-censored KGS $(93.0 \%$ versus 90.1\%) rates were comparable between the older and younger recipient groups, respectively. Similar to our study, they reported no differences in the incidences of DGF, acute rejection, surgical complications, or readmissions between the 2 groups. With follow-up ranging from 1-6 years, they also identified DWFG as the most common cause of graft loss in the older group and cardiovascular disease as the major cause of death [47]. No differences were noted in patient or KGS (both uncensored and censored) rates with follow-up to 5 years.

A number of recent studies have attempted to identify recipientrelated risk factors that predict outcomes in the elderly [3-19]. The reluctance to refer older patients for transplantation in comparison to younger patients is generally attributed to the desire to maximize graft survival and longevity, which is decreased in the long-term in the elderly primarily due to DWFG $[12,48]$. However, when censoring for DWFG, several studies including our own have shown that KGS in the elderly is either equivalent or even improved compared to younger recipients [3-19,48].

The primary co-morbidities responsible for DWFG are cardiovascular disease, infection, and malignancy [3-19,48]. It follows from our study and others that appropriate recipient selection with aggressive pre-transplant screening and post-transplant monitoring are paramount to improve the safety and effectiveness of KT in the older ESRD population. Proper identification and management of risk factors for DWFG such as smoking, congestive heart failure, cardiac function and arrhythmias, obesity, diabetes, and hypertension are indicated [3-17,49,50]. Clearly, however, an accurate and reproducible assessment of "physiological" age rather than "chronological" age is needed in order to guide appropriate recipient selection. Another important and under-recognized issue is the need to re-evaluate older patients on the waiting list more frequently because advanced age is also a risk factor for the development of either disqualifying features or death in the absence of timely KT [6-13]. In spite of a greater burden of co-morbidities in the older group in our study, when controlling for donor quality, no significant differences were noted in outcomes after a mean follow-up of 58 months. Because the numbers are small and the design is retrospective, we cannot convincingly show that donor and recipient age and longevity matching are warranted in order to improve organ utilization and optimize outcomes.

In summary, our single-center study using a paired-kidney analysis supports the contention that $\mathrm{KT}$ is a viable therapeutic modality for elderly ESRD patients, particularly with marginal donor kidneys that may not necessarily be appropriate for younger recipients who have greater projected long-term survival. A highly organized pretransplant screening, selection, and waitlist monitoring process coupled with a robust immunosuppressant protocol and intensive post-transplant surveillance ensures that kidneys transplanted into the elderly are used to their full potential and truly enhance quality of life and life expectancy without necessarily compromising graft life-years.

\section{References}

1. Matas AJ, Smith JM, Skeans MA, Lamb KE, Gustafson SK, et al. (2013) OPTN/SRTR 2011 Annual Data Report: kidney. Am J Transplant 13 Suppl 1: 11-46.

2. Wolfe RA, Ashby VB, Milford EL, Ojo AO, Ettenger RE, et al. (1999) Comparison of mortality in all patients on dialysis, patients on dialysis awaiting transplantation, and recipients of a first cadaveric transplant. $\mathrm{N}$ Engl J Med 341: 1725-1730.

3. Jassal SV, Krahn MD, Naglie G, Zaltzman JS, Roscoe JM, et al. (2003) Kidney transplantation in the elderly: a decision analysis. J Am Soc Nephrol 14: 187-196.

4. Fabrizii V, Winkelmayer WC, Klauser R, Kletzmayr J, Säemann MD, et al. (2004) Patient and graft survival in older kidney transplant recipients: does age matter? J Am Soc Nephrol 15: 1052-1060.

5. Abecassis M, Bridges ND, Clancy CJ, Dew MA, Eldadah B, et al. (2012) Solid-organ transplantation in older adults: current status and future research. Am J Transplant 12: 2608-2622.

6. Knoll GA (2013) Kidney transplantation in the older adult. Am J Kidney Dis 61: 790-797.

7. Doyle SE, Matas AJ, Gillingham K, Rosenberg ME (2000) Predicting clinical outcome in the elderly renal transplant recipient. Kidney Int 57: 2144-2150.

8. Cardinal H, Hebert MJ, Rahme E, Houde I, Baran D, et al. (2005) Modifiable factors predicting patient survival in elderly kidney transplant recipients. Kidney Int 68: 345-351.

9. Faravardeh A, Eickhoff M, Jackson S, Spong R, Kukla A, et al. (2013) Predictors of graft failure and death in elderly kidney transplant recipients. Transplantation 96: 1089-1096.

10. Furian L, Rigotti P (2013) Transplantation: Optimizing outcomes in elderly kidney transplant recipients. Nat Rev Nephrol 9: 382-384.

11. Hatamizadeh P, Molnar MZ, Streja E, Lertdumrongluk P, Krishnan M, et al. (2013) Recipient-related predictors of kidney transplantation outcomes in the elderly. Clin Transplant 27: 436-443.

12. Gill JS, Schaeffner E, Chadban S, Dong J, Rose C, et al. (2013) Quantification of the early risk of death in elderly kidney transplant recipients. Am J Transplant 13: 427-432. 
Citation: Farooq U, Al-Shraideh Y, Katari R, Farney AC, Rogers J, et al. (2014) Single Center Experience with Deceased Donor Kidney Transplantation in Patients Aged 70 and Older: A Matched-Pair Cohort Study. J Transplant Technol Res 4: 135. doi: 10.4172/2161-0991.1000135

Page 7 of 7

13. Karim A, Farrugia D, Cheshire J, Mahboob S, Begaj I, et al. (2014) Recipient age and risk for mortality after kidney transplantation in England. Transplantation 97: 832-838.

14. Ponticelli C (2000) Should renal transplantation be offered to older patients? Nephrol Dial Transplant 15: 315-317.

15. Oniscu GC, Brown H, Forsythe JL (2004) How old is old for transplantation? Am J Transplant 4: 2067-2074.

16. Nunes P, Mota A, Parada B, Figueiredo A, Rolo F, et al. (2005) Do elderly patients deserve a kidney graft? Transplant Proc 37: 2737-2742.

17. Bunnapradist S, Danovitch GM (2010) Kidney transplants for the elderly: hope or hype? See comment in Clin J Am Soc Nephrol 5: 1910-1911.

18. Johnson DW, Herzig K, Purdie D, Brown AM, Rigby RJ, et al. (2000) A comparison of the effects of dialysis and renal transplantation on the survival of older uremic patients. Transplantation 69: 794-799.

19. Giessing M, Budde K, Fritsche L, Slowinski T, Tuerk I, et al. (2003) "Oldfor-old" cadaveric renal transplantation: surgical findings, perioperative complications and outcome. Eur Urol 44: 701-708.

20. Shin M, Park JB, Kwon CH, Joh JW, Lee SK, et al. (2013) Enhanced significance of donor-recipient age gradient as a prognostic factor of graft outcome in living donor kidney transplantation. World J Surg 37: 1718-1726.

21. Frei U, Noeldeke J, Machold-Fabrizii V, Arbogast H, Margreiter R, et al. (2008) Prospective age-matching in elderly kidney transplant recipients-a 5-year analysis of the Eurotransplant Senior Program. Am J Transplant 8: 50-57.

22. Tullius SG, Tran H, Guleria I, Malek SK, Tilney NL, et al. (2010) The combination of donor and recipient age is critical in determining host immunoresponsiveness and renal transplant outcome. Ann Surg 252: 662-674.

23. Humar A, Denny R, Matas AJ, Najarian JS (2003) Graft and quality of life outcomes in older recipients of a kidney transplant. Exp Clin Transplant 1: 69-72.

24. Kontodimopoulos N, Niakas D (2008) An estimate of lifelong costs and QALYs in renal replacement therapy based on patients' life expectancy. Health Policy 86: 85-96.

25. Rebollo P, Ortega F, Baltar JM, Díaz-Corte C, Navascués RA, et al. (1998) Health-related quality of life (HRQOL) in end stage renal disease (ESRD) patients over 65 years. Geriatr Nephrol Urol 8: 85-94.

26. Grams ME, Kucirka LM, Hanrahan CF, Montgomery RA, Massie AB, et al. (2012) Candidacy for kidney transplantation of older adults. J Am Geriatr Soc 60: 1-7.

27. Schold J, Srinivas TR, Sehgal AR, Meier-Kriesche HU (2009) Half of kidney transplant candidates who are older than 60 years now placed on the waiting list will die before receiving a deceased-donor transplant. Clin J Am Soc Nephrol 4: 1239-1245.

28. O'Hare AM (2012) Age and access to kidney transplantation. J Am Geriatr Soc 60: 151-153.

29. Grams ME, McAdams Demarco MA, Kucirka LM, Segev DL (2012) Recipient age and time spent hospitalized in the year before and after kidney transplantation. Transplantation 94: 750-756.

30. Ojo AO, Hanson JA, Wolfe RA, Leichtman AB, Agodoa LY, et al. (2000) Long-term survival in renal transplant recipients with graft function. Kidney Int 57: 307-313.

31. Rao PS, Merion RM, Ashby VB, Port FK, Wolfe RA, et al. (2007) Renal transplantation in elderly patients older than 70 years of age: results from the Scientific Registry of Transplant Recipients. Transplantation 83: 1069-1074.

32. Heldal K, Hartmann A, Grootendorst DC, de Jager DJ, Leivestad T, et al. (2010) Benefit of kidney transplantation beyond 70 years of age. Nephrol Dial Transplant 25: 1680-1687.

33. Huang E, Poommipanit N, Sampaio MS, Kuo HT, Reddy P, et al. (2010) Intermediate-term outcomes associated with kidney transplantation in recipients 80 years and older: an analysis of the OPTN/UNOS database. Transplantation 90: 974-979.

34. Boesmueller C, Biebl M, Scheidl S, Oellinger R, Margreiter C, et al. (2011) Long-term outcome in kidney transplant recipients over 70 years in the Eurotransplant senior kidney transplant program: A single center experience. Transplantation 92: 210-216.

35. Guarrera JV, Samstein B, Aziz F, Kelly J, Hardy MA, et al. (2011) Excellent outcomes of renal transplantation in patients 70 years of age or older. Dialysis \& Transplant 40: 124-125.

36. Metzger RA, Delmonico FL, Feng S, Port FK, Wynn JJ, et al. (2003) Expanded criteria donors for kidney transplantation. Am J Transplant 3 Suppl 4: 114-125.

37. Moore PS, Farney AC, Hartmann EL, Rogers J, Doares W, et al. (2007) Experience with deceased donor kidney transplantation in 114 patients over age 60. Surgery 142: 514-523.

38. Stratta RJ, Rohr MS, Sundberg AK, Farney AC, Hartmann EL, et al. (2006) Intermediate-term outcomes with expanded criteria deceased donors in kidney transplantation: a spectrum or specter of quality? Ann Surg 243: 594-601.

39. Farney AC, Doares W, Rogers J, Singh R, Hartmann E, et al. (2009) A randomized trial of alemtuzumab versus antithymocyte globulin induction in renal and pancreas transplantation. Transplantation 88: 810-819.

40. Dei Cas A, Gnudi L (2012) VEGF and angiopoietins in diabetic glomerulopathy: how far for a new treatment? Metabolism 61: 1666-1673.

41. Abecassis M, Bartlett ST, Collins AJ, Davis CL, Delmonico FL, et al. (2008) Kidney transplantation as primary therapy for end-stage renal disease: A National Kidney Foundation/Kidney Disease Outcomes Quality Initiative (NKF/KDOQITM) conference. Clin J Am Soc Nephrol 3: 471-480.

42. Traynor C, O'Kelly P, Denton M, Magee C, Conlon PJ (2012) Concordance of outcomes of pairs of kidneys transplanted into different recipients. Transpl Int 25: 918-924.

43. Kayler LK, Magliocca J, Zendejas I, Srinivas TR, Schold JD (2011) Impact of cold ischemia time on graft survival among ECD transplant recipients: a paired kidney analysis. Am J Transplant 11: 2647-2656.

44. Doshi MD, Garg N, Reese PP, Parikh CR (2011) Recipient risk factors associated with delayed graft function: a paired kidney analysis. Transplantation 91: 666-671.

45. Giessing M, Fuller TF, Friedersdorff F, Deger S, Schmidt D, et al. (2010) Comparison of first and second kidney transplants from the same deceased donor. Nephrol Dial Transplant 25: 4055-4061.

46. Giblin L, O'Kelly P, Little D, Hickey D, Donohue J, et al. (2005) A comparison of long-term graft survival rates between the first and second donor kidney transplanted - the effect of a longer cold ischaemic time for the second kidney. Am J Transplant 5: 1071-1075.

47. Debska-Sslizie AA, Jankowska MM, WoÅ,yniec W, Zietkiewicz M, Gortowska M, et al. (2007) A single-center experience of renal transplantation in elderly patients: a paired-kidney analysis. Transplantation 83: 1188-1192.

48. Kahwaji J, Bunnapradist S, Hsu JW, Idroos ML, Dudek R (2011) Cause of death with graft function among renal transplant recipients in an integrated healthcare system. Transplantation 91: 225-230.

49. Meier-Kriesche HU, Arndorfer JA, Kaplan B (2002) The impact of body mass index on renal transplant outcomes: a significant independent risk factor for graft failure and patient death. Transplantation 73: 70-74.

50. Tapiawala SN, Tinckam KJ, Cardella CJ, Schiff J, Cattran DC, et al. (2010) Delayed graft function and the risk for death with a functioning graft. J Am Soc Nephrol 21: 153-161. 